\title{
INGENIERÍAS LINGÜÍSTICAS Y GLOBALIZACIÓN DE LA TRADUCCIÓN
}

\author{
José Mayoralas García \\ Universidade de Vigo - Espanha \\ josemg@uvigo.es
}

Resumen: Como la Globalización, último avatar del Progreso, supone un conjunto de procesos acelerados que pretenden capitalizar la totalidad de discursos y la totalidad de sentidos robotizándolos mediante la llamada "traducción automática", urge recordar que los polisistemas (lenguas naturales en sentido amplio) son eminentemente simbólicos, escasamente lógicos y difícilmente homologables entre sí. A lo sumo, puede llegarse a una aproximación isomórfica. Es más, como la mayoría de los discursos se presentan ya 'convenientemente' (mal-)tratados o (para-)traducidos, el traductor in-formado debe servir de antídoto al fantasma totalizador de la (des)programación a ultranza que capitaliza la «aldea global» con su traducción multiusos. ¿Una (sola) lengua común con muchas 'ramificaciones' especulares repitiendo en eco más de lo mismo? ¿Es eso la globalización?

Palavras chave: Globalización, homosemantismo, (para-)traducidos, traducción automática, ingeniería lingüística,

\begin{abstract}
Globalisation, the latest avatar of Progress, involves a set of accelerated processes with the intention of capitalizing the whole of discourse and the totality of meanings, turning them into automata by means of what has been termed "automatic translation". Therefore there is an urgent need to remember that polysystems (natural languages in a wide sense) are eminently symbolical, scarcely logical and difficult to validate among themselves. What is more, as most discourse is presented already 'conveniently' (mal)treated or (para)translated, the in-formed translator should be the antidote against the totalising ghost of (de)programming rampant in the "global village" and its multi-purpose translation. Is there one (single) common language with several mirroring 'ramifications' repeating the same message over and over again as an echo? Is this globalisation?
\end{abstract}


Keywords: Globalization, homosemantism, (para)translation, authomatic translation, multifunctional translation, paraphrases, linguistic engineering, screen translation, audiovisual empire.

\section{Introducción: Ingeniería lingüística y paratraducción prêt- à-porter}

El escritor romántico Vladimir Odoevskij escribió la historia de un hombre que, para su desgracia, veía y oía absolutamente todo. Tan invansora información acabó por abrumarlo de tal modo, que era incapaz distinguir en medio de aquella profusión de imágenes y de sonidos. Había anticipado la hipertrofia de Funes, el memorioso compulsivo de Borges, prototipo de algún que otro cyber-ciudadano actual, incapaz ya de distinguir el suave matiz de un sonido diferente; y también al móvil y a la traducción automática, que amalgaman/reducen/traducen todo mensaje y todo usuario a la in-diferencia homosemántica. A esa amalgama heteróclita es lo que nosotros hemos dado en llamar aquí, de manera un tanto paradójica, homosemantismo de la globalización. Y es que cualquier proliferación o traducción indiscriminada acaba obviando el matiz para homologar todo. Lo que parafraseado de nuevo vendría a significar que vivimos en medio de un uniformante homosemantismo globalizador que diluye toda diferencia en mecánicas (para)traducciones (lingüísticas o audiovisuales) prêt-à-porter.

Así las cosas, el inédito avance de las más sofisticadas tecnologías, que van de la mano de toda una nueva ingeniería lingüística, amenazan con mecanizar/automatizar la traducción de manera indiscriminada vía cybertraducción y vía traducción audiovisual permanente, esa hidra de mil cabezas: diarios y tele-diarios, video-juegos, doblajes, publicidad, spots, etc. P. Bourdieu habla de «coerción simbólica». Adelantándonos a posteriores razonamientos, podemos avanzar ya aquí que tal proliferación de glosas, paráfrasis o paratraducciones, justo es recalcarlo, diluyen u obnubilan un patrón original cada vez más diferido, difuso e ilocalizable por 
desconocido. Lo que queremos significar con todo ello es que estamos permanentemente ante algo real, duro y camuflado, pero dado a leer mediante traducciones ad libitum, razón por lo cual debemos adoptar un inteligente margen de reticencia ante glosas o paráfrasis de un original (¿virtual?) que se ausenta cada vez bajo sus (para)traducciones técnicas.

Es ya un lugar común subrayar que razones de tipo pragmático (táctico o estratégico) enmascaran el discurso ${ }^{1}$ de cada época histórica. Decía el gran psicoanalista francés J. Lacan que no hay un solo discurso en el que no predomine el semblante. Sin contar las estrategias traductológicas llevadas a cabo por algunos trujimanes ${ }^{2}$ al correr de los tiempos. Y en este cybermundo que nos está tocando vivir, los nuevos magos o prestidigitadores de las tecnologías digitales, queriéndolo o no, son maestros en el arte de diseñar discursos para inculcarnos una percepción ad hoc. Más concretamente: hoy por hoy todo es traducción. Como decíamos al comienzo, ningún fenómeno se da a leer tal cual. Por los tiempos que corren y en sentido amplio, periodistas, presentadores, contertulios, profesores, etc., somos "traductores" condicionados por técnicas digitales dentro de márgenes o posibilidades pragmáticas (políticofinancieras). En efecto, el mercado global pone en marcha una voraz "industria de la traducción" a la que las Facultades de traducción deben ceñirse. ¿Cómo, en qué condiciones y hasta qué punto? Es más; ¿cuál es el papel -y la responsabilidad- de la traducción y de la paratraducción en todo esto?

\section{Mercado global y traducción industrial}

Por todo ello, a lo largo del artículo demostraremos cómo también en esta acelerada, hetero y diglósica "autopista de la información" por la que navegamos (el cibermundo de P. Virilio), todo es traducción o presumiblemente tal. Todo el mundo político-financiero (o poderes públicos) está interesado en que todo esté "conve- 
nientemente" traducido. Tarde habla de esas tecnologías de la velocidad, de la transmisión y del contagio que todo lo fagocitan. Y Savater se queja de un «racismo tecnológico que intenta extender a todos la castración que padece y a la que llama 'eficacia'»'. En lo que a la traducción respecta, dicha eficacia está catapultada, ya lo hemos dicho, por una sofisticada ingeniería lingüística que persigue encontrar las claves de una "traducción automática" que funcione ad libitum. Todo ello bajo supervisión de un capital económico que acaba por convertir a la inteligencia artificial y a la traducción automática en su punta de lanza. ¿Quiere esto decir que la "economía de mercado a ultranza" determina cómo debe ser la traducción de la globalización y su correspondiente e importantísima puesta en escena audiovisual? La respuesta es que sí, razón por la cual todo ciudadano avispado tendrá interés en conocer sus entresijos. $\mathrm{Y}$ es que permanentes mecanismos comerciales de cálculo y traducción industrial hacen invisibles el trasvase del original a sus respectivos sucedáneos mediáticos o de cualquier otro tipo. ¿Qué ventajas y peligros acarrearea tan permanente trasvase? El peligro acecha cuando determinadas culturas, vía indirecta de la traducción multiusos, han ido modificando su idiosincrasia hasta volverla irreconocible e inespecífica.

Mutatitis mutandis y amén de esos "peligros" arriba reseñados, volvemos a preguntarnos: ¿qué excesos o "malformaciones" genera la profusa y difusa industria de la traducción automática y audiovisual en la que nos movemos y a la que, prácticamente, el común de los mortales sólo tenemos acceso? Sabido es que el exceso de dióxido de carbono produce el calentamiento global y el exceso de vitamina A influye en el individuo creándole malformaciones. Cuando los niveles de securina, una proteína presente en las células humanas (cuyo nombre científico es hPTTG1), son muy altos, dicha proteína genera tumores, según un informe publicado en la revista Nature Genetics y firmado por José Antonio PintorToro, investigador del Instituto de Recursos Naturales y Agrobiología del CSIC. Haciendo nuestros los postulados de Grice, insistimos en que la ingente traducción humana e industrializada 
debe estar acompañada de cualidad, relación y manera. Cada día vamos teniendo más datos acerca de sonados estragos traductológicos a todo los niveles y en todas las capas de las logoesfera. Sin ir más lejos, ¿qué decir cuando se sustituye o traduce "bombardear al enemigo" por ese eufemístico "causar daños colaterales" que la globalización impone? Lo mismo ocurre cuando se reemplaza "campo de batalla" por el descafeinado "teatro de operaciones". iAh, sabido es que un "error lingüístico" permitió que la Comisión Europea aprobara la patente para clonar células humanas!

\section{Para-traducir lo "políticamente correcto"}

Con el fin de ir ilustrando cuanto acabamos de señalar, ahondemos en el anverso y reverso de una traducción automático-industrial que sólo puede sostenerse por el mercado de la globalización y de sus avances científico-técnicos: nos referimos a la anhelada traducción automática guiada por inteligencia artificial. Todo ello coronado por la omnímoda paratraducción audiovisual entendida como un sofisticado mecanismo que sirve para globalizar la información que vehicula et non solum... Sirviéndonos del manido símil del iceberg, puede que descubramos, in fine, que de la "traducción de la globalización", sólo emerge la parte menos importante, lo que interesa queda debajo y no se deja ver... Y es que, insistimos, es tal la distancia que separa al original de sus glosas, paráfrasis o traducciones (audiovisuales), que si pudiésemos detectar todo lo que subyace o se pierde detrás de tanta ingeniería y de tan baja calidad lingüística, quizás descubriésemos despavoridos cuanto se camufla tras una supuesta "transparencia informativa" supervisada por el depuradísimo "political correctness". Si tuviésemos tiempo, recursos y opción para detectar el abismo que separa al 'tema' de la 'versión' dada a conocer, el fraude nos parecería intolerable. Pero para ello habría que traspasar el Significante audible de los medios de comunicación a fin de acceder a la marca muda de los poderes 
público que escriben, dicen y esconden al mismo tiempo 'otra cosa' a través de él.

En tales circunstanciuas, ¿se puede conocer o tener acceso al original? Para ello habría que servirse, también, de un subterfugio. Habría que hacer el camino de vuelta, retroceder hasta el punto de partida, hasta aquello que dio lugar a las traducciones en todas sus manifestaciones. E. A. Poe decía que tras haber situado a sus personajes en in medias res, daba marcha atrás para indagar cuál era la causa del conflicto. Si lo imitásemos, objetivaríamos los motivos, las causas, y comprenderíamos por qué ahora resulta que, para colmo, ini siquiera se encuentra ya la (supuesta) grabación original del (supuesto) alunizaje de 1968 (que muchos vimos como original)!

Como son escasos los privilegiados que tienen tiempo y acceso directo al hecho en sí, ya sea porque desconocen la lengua fuente (de la globalización), ya porque ignoran los distintos "ergolectos" o lenguajes especializados de las más de cuatro mil disciplinas y subdisciplinas científicas, sin contar áreas y sub-áreas de toda una especialización por la especialización que U. Eco satirizaba con su ya famoso «Departamento de tetrapilectomía» o arte de buscarle tres pies al gato; y como 'traducir' viene de tansducere: conducir, llevar a otro lado; cuando algo importante llega hasta la mayoría de nosotros, ya ha sido convenientemente (mal)tratado, trasladado o paratraducido por toda una ingeniería y unos medios de comunicación muy dependientes de los llamados poderes públicos, muy pendientes, a su vez, de lo "políticamente correcto".

\section{Peldaños de la traducción: general, automática y especializada}

Así las cosas, las Facultades de Traducción, a caballo entre traducción general y especializada y conscientes de que la traducción científico-técnica para profesionales y la general no caminan 
cada una por su lado, preparan a futuros traductores multiusos que hagan de 'intérprete' en una o en varias direcciones. Y es que todo traductor sabe que, rara vez o sólo en teoría, se va a encontrar con un lenguaje coloquial o con un lenguaje científico por separado. Tal dicotomía, conviene no engañarse, es sólo una cómoda simplificación didáctico-metodológica: los especialistas conceden sólo un 10\% de vocabulario técnico a los textos de lenguaje especializado. Así por ejemplo, todo traductor de Einstein debe saber que éste explicaba el efecto fotoeléctrico por medio de cuantos de luz, corpúsculos energéticos que él llama fotones, y para-traducirlo en román paladino (con el cual cada uno puede entenderse con su vecino), resumía dicha jerga en un símil coloquial que todos captamos: este haz de luz es un chorro de corpúsculos. También en medicina el llamado Sindrome de Cushing reagrupa diversas lipodistrofias, pero al ciudadano de a pie nos lo traducen por "cojín de grasa" o "joroba de búfalo". El traductor debe moverse siempre entre la jerga especializada y el el lenguaje de uso común. Esto es, traducción general y especializada se presentan como las dos caras de Jano. Cualquier texto científico o artículo de contenido psicológico, químico o farmacéutico las combina. Habría que remitirse al puro manual de instrucciones o a la traducción de una patente ${ }^{4}$ industrial para ceñirse escrupulosamente a la traducción técnica propiamente dicha. Así por ejemplo, no queda más remedio que deslindar patente de modelo de utilidad (francés: brevet et certificat d'utilité), ya que el primer tecnicismo implica una propiedad intelectual ${ }^{5} \mathrm{de}$ 20 años para la patente (brevet) y de 10 años para el modelo de utilidad.

Dicho lo cual cabe preguntarse ¿existe un solo tratado de filosofía, periódico, folleto, artículo, película, traducción, doblaje, etc. cuya pureza lingüística sea fruto exclusivo de un logos trascendental o de una absoluta jerga técnica? El problema, afortunadamente para nosotros, es que estamos muy lejos del sueño cientista inaugurado por Gottlob Frege, que abogaba por un significado objetivo del signo, desamarrado de connotaciones o contingencias. De ser así, la traducción automática hace tiempo que habría logrado su objeti- 
vo isomórfico. Nadie ha dado con la "norma" de ese lenguaje desencarnado, sin transposiciones ni transgresiones categoriales, similar a un esqueleto sin músculos y sin nervios, ideal hacia el que tiende la comunicación por móvil y la traducción automática. El sacrificio del "engrema" y del estilo en aras a un lenguaje científico no fue suficiente para supeditar el discurso al riguroso ascetismo positivista ni tecnológico. Entre la fijación del diccionario o del sofweare y la idiomaticidad de la que habla Lubomir Bartos ${ }^{6}$, existe un abismo infranqueable para la inteligencia artificial y para la traducción por ordenador. El vagabundeo semántico -expresión acuñada por Derrida- es inherente a la plasticidad adecuativa con la que cuenta el cerebro humano. Por si fuera poco, "si el pensamiento "lógico" del ordenador difiere del pensamiento del sujeto hablante es porque prolifera en un desierto absoluto de goce; la información que aporta el bit no posee la capacidad, propia de la letra, de servir de sustancia capaz de acoger el goce" ${ }^{\text {. }}$ Y el reto del traductor y del hombre del siglo XXI es dilucidar cómo compaginar goce y rentabilidad a fin de frenar ese horror que Peter Sloterdijk ${ }^{8}$ llama «l'ère du monstrueux créé par l'homme».

\section{Nunca la traducción automática podrá equiparar mecánicamente a los polisistemas}

En su base, los polisistemas (lenguas naturales en sentido amplio) son eminentemente simbólicos, escasamente lógicos y difícilmente homologables traductológicamente hablando 9 . De igual modo, su taxonomía, su trasvase o tratamiento automático-universal mediante la robotizada "inteligencia artificial" es igual de insuficiente y de problemático que el proveniente del, hasta hace poco, «Schleicherian Paradigm», base de la tradicional traducción académico-universitaria. En cualquier caso, ambos métodos traductológicos tienden a homologar el todo por la parte y a todos por la base. Un poco a la manera de esas caricaturas de mensajes 
estereotipados que se transmiten por móvil. Y ello porque una universalizante traducción automática, sueño cientista de una pura materialidad (informatizada) que ejecute el texto mecánicamente, esto es, al margen del traductor como socius o intermediario cultural, lográndose así la tan anhelada objetividad, acaba traduciendo indiscriminadamente lo que le echen. Un robot traductológico, al que le han perpetrado una buena base de datos para que genere traducciones ad libitum, lo convierte, para entendernos, en algo así como un lavavajillas, que lava todo lo que le echen, sin importarle si la loza está limpia o sucia. ¿Incumbe al traductor-lector reconsiderarlo? Para la traducción, como para cualquier organismo vivo o cualquier sistema social (país, ciudad, facultad de traducción, gran empresa, etc.) la regulación total es imposible y la improvisación más nefasta aún. El pensamiento único surge del idioma único.

¿Por qué tamaño empeño en globalizar/robotizar la traducción y, de paso, evacuar al sujeto-traductor? ¿Es sólo por razones científicas y de rentabilidad? Hay que (pro)poner remedios para no quedar atrapados en la larga noche del solipsismo o "barbarie ritornata" contra la cual alertaba ya lúcidamente Vico en pleno el siglo XVII. ¡Lejos de nosotros querer convertirnos en esos laudatores temporis acti (que alaban el tiempo pasado) para desestimar la utilidad del diccionario en cederrón o prescindir de los impagables servicios que prestan los "tutores inteligentes" cuando se enfocan hacia el "aprender inventando" (de J. Piaget)! Ahora bien, urge saber qué se puede (no) hacer y hasta dónde (no) se debe llegar con el sofware y la documentación digital ${ }^{10}$, la terminología e ingeniería del conocimiento, las Tecnologías de la Información y la Comunicación (TIC) aplicadas a la traducción: La Tradumática. Para la traducción, como para cualquier organismo vivo o cualquier sistema social (país, ciudad, facultad de traducción, gran empresa, etc.) la regulación total es imposible y la improvisación más nefasta aún.

Como la globalización, último avatar del Progreso, supone un conjunto de procesos acelerados de orden político-social, económico, tecno-traductológico, etc., que pretenden capitalizar la totali- 
dad de discursos y la totalidad de sentidos gracias a la llamada "inteligencia artificial", urge formar al traductor que sirva de antídoto al fantasma totalizador de la (des)programación a ultranza que capitaliza la «aldea global» del telegráfico mensaje por móvilmultiusos, convertido en nuestro deus ex machina... Sólo así se conseguirá contrarrestar una realidad (¿virtual?) cuya forma más dramática la constituye el cómputo de un número que seduce en serie y cuya fuerza es la estadística de la manipulación combinatorio-informático-informativa. Cabe luego interrogarse acerca del riesgo que supone la actual cohabitación del llamado pensamiento débil con el lenguaje macizo del fortísimo imperio audiovisual. Eso lo saben muy bien los poderes públicos y las agencias que diseccionan, mutilan y repiten las mismas noticias periódica e intermitentemente a través de "radio-fórmulas", "spots", "flasches" etc..

Un mínimo de perspicacia nos advierte de que estamos permanentemente frente a una desconocida realidad original que siempre se diluye: entre los intersticios de palabras vagas con sentidos particulares, neologismos eufemísticos, elipsis sintácticas, fundidos encadenados, etc. De ahí que vengamos reiterando que toda verdadera traducción es resistencial... Traducir es un trabajo de desciframiento, casi detectivesco o psicoanalítico. A raíz de tales consideraciones, cabe de nuevo preguntarse, aunque no siempre pueda responderse: ¿Qué circula y qué se vehicula más allá de toda una serie de traducciones multiusos que se desparraman en todo tipo de folletos informativos, periodismo (de investigación), congresos, artículos en revistas especializadas, telediarios, video-juegos, etc.? ¿Velan o desvelan el susodicho original? ¿A partir de qué original leemos una noticia en el periódico o escuchamos una noticia en el telediario? Y todo el problema está ahí: ¿qué nos llega a través del artículo periodístico entendido como traduccción de un original (incompleto)? En cuyo caso ¿cuál es la hiancia que separa al textofuente del texto-meta? Eso sólo lo saben los poderes públicos y quizás las agencias que diseccionan, mutilan y repiten las mismas 
noticias periódica e intermitentemente a través de "radio-fórmulas", "spots", "flasches" etc..

\section{Y como colofón, un ejemplo ilustrativo de todo ello}

Vamos a ilustrarlo con un conocido episodio aún reciente. E. Torrejón Díaz ${ }^{11}$ cuenta cómo periódicos y telediarios informaron (subrepticia y escuetamente) acerca del ya legendario avión que se estrelló en Turquía en el 2002. Al común de los mortales se nos dijo a toda hora que tal accidente lo causó un "fallo técnico". Pero toda una "vulgata didáctica" de la comunicación 'obvió' añadir, luego del 'traslado' a su difusión mediática, que una mala traducción turca había obstaculizado "los controles de calidad" a los operarios, ofreciéndosenos ya así una noticia 'recortada' (sesgada) del accidente aéreo como proveniente de un exclusivo fallo técnico. Por ello, estar más informado no significa estar mejor informado. Tras lo cual, varias 'inferencias' se imponen en cascada. En primer lugar, como los operarios trabajaron ineficazmente con la mala traducción de un original in absentia, el temido "conflicto comunicativo" ("communication conflict") acarreó el mortal "fallo técnico". Y "last but not least”, los medios de comunicación no consideraron "relevante" informar (completamente) del por qué del "fallo técnico". Dieron, pues, una noticia no-toda emanada de una traducción deficiente (no-toda). Sólo con obviar datos resulta fácil hacer creer lo que interesa. Manejar la información es manejar la opinión. Tras la cortina de imágenes seleccionadas, quedan sepultadas las verdaderas causas de los acontecimientos mediatizados. Lo cual ilustra y confirma cómo una información no-toda dificulta -pero no impide- que se pueda 'infierir' la brecha que separa lo "dicho" de lo implícito o implicado.

En tales casos los lingüistas hablan de diátesis para dar cuenta de cómo determinada focalización eventiva obedece a determinadas "estrategias comunicativas" plagadas de omisiones. Digamos 
que la 'redundancia' informativa fue inversamente proporcional a la compresión de los datos silenciados o sustraídos. En el caso del avión turco como en otros tantos casos se paga caro que la traducción no sea, en palabras de J.C. Catford, "la sustitución del material textual de una lengua por material textual equivalente de otra". Fallo lingüístico y fallo técnico constituyen el anverso/reverso de la misma medalla. Lo cual se tradujo finalmente en víctimas mortales seguida de una pseudo-información catastrófica. De haberlo contado todo, se hubiera podido entender, de verdad, el "fallo técnico". Y la pregunta no se hace esperar: ¿cómo garantizar en todo momento la perfecta equivalencia entre lengua-fuente y lenguameta seguida de su fideligna retransmisión audiovisual falsamente repetida como eco?

\section{Conclusiones}

El 'carácter sucedáneo o derivado' de esta sociedad de la representación tecnológica, privada ya de escenario (humano), permite a los llamados "poderes públicos" prever e impedir (desde otra escena) que nos demos cuenta de que somos traducido-manipulados. Las turbias aguas de la «New Age» son cada vez propicias para este tipo de mixtificaciones: alunizaje, telefilmes, telenovelas, realities, video-juegos subtitulados, etc. Sin embargo, no hay porqué alarmarse demasiado, la física cuántica aseveró que un elemento aleatorio preside cualquier selección o configuración, revalidando así el principio de 'incertidumbre' introducido por la constante de Planck. En The Poverty of Historicism (1957), K. Popper considera que cualquier acontecimiento histórico-social de envergadura genera dos efectos contrapuestos: el demandado y el temido o no deseado. Así pues, esperemos que este "paroxysme de l'excès" (Michel Maffesoli) u "order from noise" (de Von Foerster) genere un nuevo original que de pie a traducciones de ida y vuelta. Lo que traducido nuevamente vendría a significar que, un acceso a 
la versión primera de los hechos podría paliar el tan temido "conflicto comunicativo" ("communication conflict") y el no menos problemático "error comunicativo" ("communication breakdown"). A la luz de tales consideraciones, Borges proponiendo a uno de sus traductores que no tradujera lo que decía, sino lo que quería decir, resuena cada vez mejor en nuestros oídos.

Mientras tanto, ¿qué hacer en medio de una "supercultura" (o cultura de culturas) y de una sola lengua común (el inglés ${ }^{12}$ ) con muchas 'ramificaciones' 13 y muchas (para)traducciones que imponen, desde arriba, industria y tecnologías a todos y a todas las demás? ¿Es eso la globalización? Traducción, traducción, hazaña suprema de esta era «cibernética» amordazada por la tecnología aplicada. Al traductor et non solum... de sacar sus propias conclusiones.

\section{Notas}

1. J. Berger, Algunos pasos hacia una pequeña teoría de lo visible, Madrid, Ardora Exprés, 2000. W. Golding, La lengua oculta, Madrid, Alianza, 1997.

2. Merece la pena recordar que, a pesar de los "apaños" llevados a cabo por el dramaturgo, crítico literario, historiador, diplomático, filólogo humanista y traductor que fue el autor de Pepita Jiménez, Valera fue amistosamente amonestado por el santón de los filólogos positivistas españoles de su época. Nos referismos al catalán Milá i Fontanals, que le reprochó el haber traducido fidelignamente algunos pasajes de Poesía y arte de los árabes en España y Sicilia de Von Schack, en estos términos « Así quisiéramos que se hubiesen modificado [isic!] ciertos paralelos del estado moral y del entusiasmo bélico religioso de los árabes y el de los cristianos; que por más que se trate de árabes, no se alabase cierto género de tolerancia, y que tuvieran el debido correctivo ciertas pullas antimonacales, únicas que al parecer disfrutan del privilegio de desarrugar el sobrecejo científico». Parece que Valera no olvidó la lección, y cuando le llega el momento de verter al castellano las Pastorales de Longus, libro en el que la ambigüedad sexual de Gnathon era patente, Valera 
censura y trasforma, por su cuenta y riesgo, a ese hombre en mujer. Oigámosle: «En el cuarto libro nos hemos atrevido a hacer bastantes alteraciones, algo parecido a lo que llaman un arreglo. Esto no quita que muchos párrafos (más de la mitad de dicho Libro IV) estén también traducidos por nosotros con la mayor exactitud. Sólo hemos variado unos lances originales por cierta pasión repugnante para nuestras costumbres, sustituyéndolos con otros fundados en más naturales sentimientos».

3. F. Savater, "Deberes y gozos de la palabra", citado por Catalina Buezo http:// www.ucm.es/info/especulo/numero21/c_buezo.html

4. Ley 11/86 de Patentes y su Reglamento de ejecución (Real Decreto 2245/86 de 10 de octubre). Dicha Ley de patentes indica claramente que los títulos de propiedad industrial hacen referencia única y exclusivamente a aplicaciones industriales, y no tienen nada que ver con lo intelectual.

5. Copyright, acompañado del símbolo ${ }^{\circledR}$, se encuentra en todo tipo de publicaciones y se suele dejar en inglés. Pero es preciso señalar que los derechos de propiedad industrial e intelectual están supeditados a las distintas legislaciones nacionales. Los traductores tienen la importante tarea de armonizar dicha terminología. Consúltese al respecto Verónica González Pérez, "Peculiaridades de la terminología de propiedad industrial e intelectual", PUNTOYCOMA, BOLETÍN DE LAS UNIDADES ESPAÑOLAS DE TRADUCCIÓN DE LA COMISIÓN EUROPEA, n ${ }^{\circ} 61$ / enero/febrero de 2000.

6. "En vista de una gran cantidad de variantes léxicas y sintagmáticas (las) que contradicen la fijación, surge la cuestión de cuál de ellas es la variante", in Lubomir Bartos, "Sobre un subtipo de fraseologismos comparativos en el checo y el español",

7. J.-Cl. Maleval, La forclusión del Nombre del Padre, Paidós, Buenos Aires, 2002, p.212.

8. Peter Sloterdijk, L'heure du crime et le temps de l'œuvre, Paris, CalmannLevy.

9. Mientras que los llamados "semas nucleares" son portadores del significado propio de las palabras, los semas contextuales o clasemas remiten a significados metonímicos o metafóricos. Recientes memorias de licenciatura y tesis doctorales en nuestras facultades de Traducción e Interpretación se ocupan, de forma esperanzada 
y fecunda, por indagar el perpetuum mobile que son los polisitemas frente a la lengua de la globalización.

10. E. Guiguet, Méthode pour l'analyse automatique des structures formelles sur documents multilangues, Thèse de doctorat en informatique, Université de Caen, 1998.

11. Enrique Torrejón Díaz es consultor técnico senior en el Departamento de Traducción, Interpretación y Lenguas Aplicadas de la Universidad Europea de Madrid.

12. $50 \%$ de las páginas web recensadas en el mundo están escritas en inglés, cuando menos del $10 \%$ de la población tiene el inglés como lengua materna.

13. Que van del libro a la revista o periódico, texto informativo, subtítulos y guiones de cine y televisión, etc.

\section{Bibliografia}

BENJAMIN, W. "L'oeuvre d'art à l'ère de sa reproductibilité technique", in Écrits français, Paris, Gallimard, 1991.

BLEICHMAR, H. Estudio sobre la enunciación y la gramática inconsciente, Buenos Aires, Nueva Visión, 1981.

BOUGNOUX, D. La communication contre l'information, Paris, Hachette, 1995.

CORPAS PASTOR, G. Manual de fraseología española, Madrid, Gredos, 1996.

FAUCONNIER, G. Mental Spaces, Cambridge MIT Press, London, 1985. 
FAUCONNIER, G. y TURNER, M. "Conceptual integration and formal expression”, in Journal of Metaphor and Symbolic Activity, vol 10, n³, 1995.

ECO, U. La búsquedea de la lengua perfecta, Barcelona, Crítica, 1999.

GARGALLO, S. Análisis contrastivo, análisis de errores e interlengua en el marco de la lingüística contrastiva, Madrid, Síntesis, 1993.

GIDDENS, A. Un mundo desbocado, Madrid, Santillana, 2000.

GUIGUET, E. Méthode pour l'analyse automatique des structures formelles sur documents multilangues, Thèse de doctorat en informatique, Université de Caen, 1998.

LAKOFF, G. JOHNSON, M. Metáforas de la vida cotidiana, Madrid, Cátedra, 1995.

LÉVY, P. La machine univers. Création, cognition et culture informatique, Paris, La Découverte, 1987.

MADERO, M. Manos violentas, palabras vedadas. La injuria en Castilla y León, siglos XIII-XV, Madrid, Taurus, 1992.

LIPOVETSKY, G. La era del vacio, Barcelona, Anagrama, 1983.

MARTÍN-BARBERO, J. De los medios a las mediciones : comunicación, cultura, hegemonía, México, Gustavo Gili, 1987.

NIETZSCHE, F. Sobre verdad y mentira en sentido extramoral, Madrid, Tecnos, 1994.

PARRET, H. "La manipulation et le mensonge", in Prolégomènes à la théorie de l'énonciation. De Husserl à la pragmatique, Peter Lang, Berne - Francfort-s.Main - New-York - Paris, 1987. 
ROUGEMONT, D. de Penser avec les mains, Paris, Gallimard, 1972.

RUIZ CASANOVA, J. F. Aproximación a una historia de la traducción en España, Madrid, Cátedra, 2000.

SANTOYO, J. C. “Los ‘estudios de traducción' en España: Estado de la cuestión y balance provisional”, en: Quaderns de Filologia. Actas del primer coloquio internacional de traductología (2, 3, 4 de mayo de 1989), editado por B. Lepinette / M. A. Olivares Pardo / E. Sopeña Balordi, Valencia 1991.

TODOROV, T. “Le sens des sons”, in Poétique, n 11, 1972, pp. 446-462.

TOFFLER, A. La tercera ola, Barcelona, Plaza \& Janés, 1980.

VIANA, L. Memoria natural y artificial, Fondo de Cultura Económica.Ciencia para Todos, México, 2002.

VIRILIO, P. Cibermundo: ¿Una politica suicida? Santiago, Dolmen Ediciones, SA , 1997. 